\title{
An exploratory qualitative study on perceptions about mosquito bed nets in the Niger Delta: what are the barriers to sustained use?
}

This article was published in the following Dove Press journal:

Journal of Multidisciplinary Healthcare

5 April 201 I

Number of times this article has been viewed

\section{Kathleen T Galvin' \\ Nick Petford ${ }^{2}$ \\ Frances Ajose ${ }^{3}$ \\ Dai Davies ${ }^{4}$}

'Bournemouth University, Talbot Campus, Fern Barrow, Poole, Dorset, UK; ${ }^{2}$ University of Northampton, Northampton, UK; ${ }^{3}$ Department of Medicine, Lagos State University and The Lagos State University Teaching Hospital, Ikeja, Lagos, Nigeria; ${ }^{4}$ Niger Delta Development Initiative, Poole, Dorset, UK
Correspondence: Kathleen T Galvin Bournemouth University, Talbot Campus, Fern Barrow, Poole, Dorset, BHI2 5BB, UK Tel +44 0 I202 962 I67

Fax +4401202962 194

Email kgalvin@bournemouth.ac.uk
Background: The effectiveness of malaria control programs is determined by an array of complex factors, including the acceptability and sustained use of preventative measures such as the bed net. A small-scale exploratory study was conducted in several locations in the Niger Delta region, Nigeria, to discover barriers against the use of bed nets, in the context of a current drive to scale up net use in Nigeria.

Methods: A qualitative approach with a convenience sample was used. One to one interviews with mostly male adult volunteers were undertaken which explored typical living and sleeping arrangements, and perceptions about and barriers against the use of the mosquito prevention bed net.

Results: Several key issues emerged from the qualitative data. Bed nets were not reported as widely used in this small sample. The reasons reported for lack of use included issues of convenience, especially net set up and dismantling; potential hazard and safety concerns; issues related to typical family composition and nature of accommodation; humid weather conditions; and perceptions of cost and effectiveness. Most barriers to net use concerned issues about everyday practical living and sleeping arrangements and perceptions about comfort. Interviewees identified were aware of malaria infection risks, but several also indicated certain beliefs that were barriers to net use.

Conclusions: Successful control of malaria and scale up of insecticide-treated net coverage relies on community perceptions and practice. This small study has illuminated a number of important everyday life issues, which remain barriers to sustained net use, and has clarified further questions to be considered in net design and in future research studies. The study highlights the need for further research on the human concerns that contribute to sustained use of nets or, conversely, present significant barriers to their use.

Keyword: malaria, Nigeria, children under 5, interviewees

\section{Rationale for the study}

Malaria remains a major threat to public health, and is the major cause of morbidity and mortality in tropical Africa. More than one million deaths per year are attributable to malaria and more than $90 \%$ occur in Sub-Saharan Africa. ${ }^{1}$ Those most vulnerable are children. ${ }^{2}$ The transmission of malaria has been extensively investigated and has informed control and treatment programs worldwide, with considerable attention paid to the positive impact of insecticide-treated bed nets (ITNs) on morbidity and mortality. Evidence for the effectiveness of ITNs is clear. Worldwide, more than 81 trials and more than 30 descriptive studies have shown the substantive health gains from ITNs. ${ }^{3}$ In addition, a growing body of literature focuses on community beliefs and behaviors 
and underscores the central importance of socio-cultural factors, knowledge, and beliefs concerning malaria control. ${ }^{4-12}$ The effectiveness of malaria control programs is determined by an array of complex factors including the acceptability and sustained use of preventative measures such as the bed net.

\section{Nigerian context}

In Nigeria, malaria remains the leading cause of death in children under 5 , comprising $33 \%$ of all childhood deaths, ${ }^{13}$ and is the leading public health burden. ${ }^{14}$ The clinical incidence of malaria has recently been reported to be on the rise, for example, there is evidence ${ }^{15}$ that the prevalence of malaria in Abia State, East Nigeria, was $61.4 \%$ in 1999 but rose to $83.0 \%$ in 2003 . Factors contributing to this significant increase include environmental conditions such as local humidity, rainfall, and temperature; the growing incidence of insecticide resistance; increasing population migration to urban areas; poor sanitation systems; inadequate health care infrastructure; poorly integrated mosquito control programs; and inadequate local knowledge and practices, for example, concerning the use of ITNs.

The Roll Back Malaria campaign was launched at the Malaria summit, held in Nigeria in 2000, with the aim of halving the burden of malaria by 2010 , and setting the "Abuja target" to increase the proportion of children under 5 and pregnant women sleeping under ITNs to $60 \%$ by $2005 .{ }^{16}$ More recently, Oresanya et $\mathrm{al}^{3}$ reported on a cross section study of 7200 households in Nigeria and concluded that progress is far from the Abuja target: household ownership of any net was $23.9 \%$ (95\% CI [confidence interval] 22.8\%-25.1\%) and $10.1 \%$ for ITNs (95\% CI 9.2\%-10.9\%). A series of surveys between 2000 and 2004 in Nigeria, Senegal, and Zambia $^{17}$ indicated that 4 years after the introduction of ITNs to the public, awareness of ITNs was almost universal in all countries except Nigeria where awareness increased from $7 \%$ to $60 \%$. All countries in the study made gains in the proportion of children under 5 sleeping under ITNs, but in Nigeria, where gains were less pronounced in 2004, 3.3\% of children under 5 were sleeping under an ITN and 17.9\% under a non-treated baby net (umbrella net).

\section{Research aims}

This small, qualitative study aimed to explore perceptions about barriers to the use of bed nets in the Niger Delta. While perceptions and socio-cultural factors have already been examined in many studies, as reported above, these remain important and timely issues as Nigeria has embarked on the largest ever "scale up" of treated nets in Africa.

\section{Methods}

We used a small-scale qualitative method, with face to face semi-structured interviews. One to one interviews, using an interview guide, were conducted with a convenience sample of 21 interviewees. All were adults and comprised a mainly male sample. The interviews were undertaken between December 2009 and February 2010. Interviewees from the following areas in the Niger Delta were invited to participate: Warri, Yenegoa, Owerri, Abua, Omoko, Obigbo, Amassona, Arhavwharien, Oqwa, and Port Harcourt. We wished to obtain a wide range of views and therefore sampled from different areas in the Niger Delta. All interviewees gave informed consent to participate, and were aware that the research would inform the development of a future study in the longer term to develop a "pop up" mosquito net. The interviewer explained in a series of community meetings, organized by local community elders, why he was in the locality, what the study was about, and that it was funded by the British Council, and asked for volunteers to participate. Mostly male adults came forward, which may reflect cultural norms regarding appropriate family advocates. The interviews lasted up to 1 hour and, using a semi-structured guide, explored these issues: typical sleeping arrangements, views about the acceptability, inconvenience, and effectiveness of the bed net, motivation to use a net, typical conditions when a net was used, typical conditions when a net was not used, factors that put people off using a net, any other aspects of the bed net that people did not like which led to non-use, and vicariously reported issues related to pregnant women and under 5 -year-olds about the use of bed nets. Several limitations of the research related to the location and context of data collection. At the time the study was conducted, Foreign Office restrictions meant that British Nationals were not permitted to enter the Delta, so that data collection had to be supervised via email contact. The interviewer was trained in the use of the guide, a semi-structured "agenda" with open questions and prompts for more detail. Questions were followed in a consistent way for each interview. The limitations of this approach arose from cultural, health, and safety challenges which meant that we had only one chance on each occasion to gather useful data. Research supervision of the interviewer was undertaken by weekly email contact. The data were transcribed when collected in the field. We were reliant on a convenience sampling method through volunteers, which meant that the sample was likely to comprise more men than women, perhaps because of cultural traditions regarding appropriate "spokespersons", although this is speculative. It was not possible in this present study to access pregnant 
women or children under 5 and we relied on issues reported from a mainly male sample, which was a significant limitation as women may act as important "gatekeepers" for family health matters. The awareness of the sample of volunteer interviewees of our interest in the limitations of the bed net and alternatives, may also have influenced their responses. Our key difficulty, influencing the overall study design, was access to the Delta region due to UK Foreign Office restrictions at the time of the study. Gender issues are likely to be important as male and female perspectives and experiences may differ. For this reason, in light of the gender sample limitations, our analysis focused on male responses and male reports of issues related to children under 5 and women. Our data are not sufficient to undertake a gender comparison, additionally mixing male and female perceptions where female interviewees were in the minority would be misleading. Therefore our analysis draws on data from the interviews that were undertaken with men.

\section{Results}

A thematic analysis was undertaken of the text generated from two thirds of the interviews to illuminate major issues and repeated themes in the data generated by male interviewees. The following summarises key findings from open ended interviews with a convenience sample of people living in the Niger Delta. Themes summarise the responses, and the words of the interviewees are reported in italics to illustrate key findings; quotes are taken from separate individual interviews to illustrate the contextual quality of the findings. The findings suggest that generally there remain a number of barriers to sustained bed net use including sleeping arrangements, perceived issues of ease of net use, safety and comfort, perceived effectiveness of repellents and coils versus nets. General issues related to everyday living are important in effective net use. Table 1 summarizes the range of responses from the data related to the themes that emerged from the data analysis.

\section{Typical sleeping and living arrangements influence sustained net use}

Most families in the present study included extended family members and, depending on economic circumstances, sleeping arrangements ranged from individual and separate bedrooms with beds, to shared rooms with a mixture of beds and foam mattresses, or mats on the floor. It was reported that breastfeeding mothers always slept with their babies and older children most often slept separately from parents, either in separate rooms or on a mattress on the floor. In polygamous relationships, interviewees indicated that women frequently had separate rooms.

\section{Nets consume space and restrict normal family activity}

In general, the acceptability of the bed net depended on space available and the number of occupants of that space. "I don't think there is anything to dislike, if you have the space and it is permanently fixed". Several interviewees indicated the need to "readjust the house", "to restructure your house setting to accommodate it", or indicated that "home is hampered" when the net is up. "It is not everywhere that you can use it, if your bed is not well positioned, giving you room to set up, you can't use it". The net limited the room for families. Over half suggested $(n=12)$ that bed net effectiveness depended on space and the number of persons living together and, as anticipated, this varied: "one's ability to manoeuvre definitely changes when it is in use"; "I live alone so it does not disrupt my routine". Respondents indicated that larger rooms with beds made the net more convenient: "works when the room is exclusive to one person, or for large room with beds". The net was considered a major disruption to everyday routines; where space was a problem the net was used only when everyone was ready to sleep, "its space consumption makes it only of use when everyone is ready to sleep"; some suggested that a window net was easier "these days because of window nets most people would not want the routine of setting up the bed net". Lack of regular electric light was also reported as a major impediment to use; access in and out of the net particularly in the dark, when electricity is limited, was a problem. "Exit and access is a problem, and if a mosquito gets in while you are trying to get through the access point it has a field day".

The nets were sometimes seen as an impediment to everyday life and some respondents indicated that "most villagers used the nets as curtains" or they were used as "containers for things". When asked if the net was inconvenient all but two reported that it was never convenient. One man said that it was convenient "only when used in doorways". In addition the net is sometimes seen as an unneeded extra and not for older adults, "the sky net is seen as a childish way of preventing malaria". In the present study, where the family lived in accommodation with a low roof, the net was considered impossible to use. Some men indicated that the net restricted sexual activity $(\mathrm{n}=2)$ : "inhibits married couples", "the net confines and limits capacity for sexual relations", and ability to get up in the night in the dark to help 
Table I Sample of data extracts to illustrate qualitative themes that emerged from analysis

\begin{tabular}{|c|c|c|}
\hline $\begin{array}{l}\text { Theme: impact of typical } \\
\text { sleeping arrangements }\end{array}$ & $\begin{array}{l}\text { Theme: nets consume space and } \\
\text { restrict normal family activity }\end{array}$ & $\begin{array}{l}\text { Theme: perceived hazards } \\
\text { and arduous set up }\end{array}$ \\
\hline $\begin{array}{l}\text { - It is convenient when the room is large and } \\
\text { has a bed so that the net can hang; better if } \\
\text { the room is exclusive to one person } \\
\text { - Mostly the children sleep on the bed with } \\
\text { the net and older children sleep on the } \\
\text { floor on foam or mat } \\
\text { - I live alone and so it [the net] does not } \\
\text { change what I do or my routine } \\
\text { - It is ok when there is a place to tie it from, } \\
\text { but better if its fixed in the bedroom if you } \\
\text { have that luxury } \\
\text { - The nets are certainly effective depending } \\
\text { on the number of persons and the size } \\
\text { of the area } \\
\text { - Not everyone can use it, if the bed is not } \\
\text { well positioned giving you room to set it up, } \\
\text { you wont be able to use it } \\
\text { is spacious }\end{array}$ & $\begin{array}{l}\text { - There is some disruption to routine, when } \\
\text { you have more persons to sleep under a } \\
\text { particular net site or bed } \\
\text { - One's ability to manoeuvre his space } \\
\text { definitely changes when the net is } \\
\text { introduced, especially hanging it daily } \\
\text { - Well, it distorts the Room } \\
\text { - It disrupts routine, gets in the way of } \\
\text { reaching for things you need from for } \\
\text { example the shelf } \\
\text { - It is inconvenient, adults can't do what } \\
\text { they want } \\
\text { - Home is hampered whenever the net is up } \\
\text { - It also inconveniences one by tying it up } \\
\text { permanently } \\
\text { - Sometimes we adjust the house setting } \\
\text { to accommodate the net }\end{array}$ & $\begin{array}{l}\text { Worries for young children } \\
\text { - I worry it will collapse and suffocate my Child } \\
\text { - It is safe to use but younger children should be } \\
\text { observed when in use } \\
\text { - Children can chew it, or get tangled in it when } \\
\text { trying to exit it } \\
\text { - Under fives need watching when using the net } \\
\text { - I think constant supervision is required } \\
\text { whenever under fives are in it because of their } \\
\text { ability to turn it into a danger to themselves } \\
\text { General hazards } \\
\text { - The nets present a safety hazard if space is limited } \\
\text { and can catch fire from lamps and Candles } \\
\text { - It is a hazard with the local lamp [fire risk] }\end{array}$ \\
\hline
\end{tabular}

a child or older person $(n=3)$. A few indicated that they did not use the net because it made it difficult to go to the toilet during the night, for example, "my urinary habits would be restrained by the net".

\section{Perceived arduous set up and hazards}

The data indicated that not everyone knows how to use a bed net or has the strength to assemble one. The task of erecting the net was sometimes considered time consuming and its assembly contributed to lack of use: "It is a frustrating process of daily settling and unsettling the net". Lack of regular electric light compounded this problem: "because of consistent power failure the net is not convenient". Many men (over half) indicated that families often rely on one person with some "technical" ability or "know how" to put up the net and if this person was ill or away, the net could not be used: "when the person who hangs and removes the net is sick or travels the others cannot use it"; "the process of setting it up makes it almost impossible for my aged mother and my pregnant wife when I am not around". Factors such as work and social activities contributed to non-use of the net. "I fish sometimes and hang out with my mates, I would have to leave them and come home to hang the net". Putting the net up was considered an extra responsibility and it was reported as impossible for older people, pregnant women and younger children: "The pro- 


\begin{tabular}{|c|c|c|}
\hline $\begin{array}{l}\text { Theme: positive and negative } \\
\text { aspects of perceived comfort }\end{array}$ & $\begin{array}{l}\text { Theme: perceptions of } \\
\text { net effectiveness }\end{array}$ & $\begin{array}{l}\text { Theme: reported benefits for young } \\
\text { families }\end{array}$ \\
\hline $\begin{array}{l}\text { Negative aspects } \\
\text { - Some spark like feeling happens when } \\
\text { some nets come into contact with your } \\
\text { hair and a lot of people dislike this } \\
\text { [static] } \\
\text { - It irritates the body when contact is } \\
\text { made with the skin } \\
\text { - The net can come into contact with } \\
\text { your skin or hair, people don't like that } \\
\text { - The net makes me feel I cannot } \\
\text { breathe well } \\
\text { - It makes me feel like suffocation } \\
\text { - Some feel it prevents the air from } \\
\text { reaching them } \\
\text { - The net prevents air from touching } \\
\text { them well } \\
\text { Positive aspects } \\
\text { - The net can keep you warm in the cold } \\
\text { season } \\
\text { - The nets prevent mosquito bite and are } \\
\text { good in the cold season for warmth }\end{array}$ & $\begin{array}{l}\text { The net versus insecticides } \\
\text {-A lot of us do not use anything because of the } \\
\text { cost of doing so constantly, N700 a week to } \\
\text { fumigate and N40 for coils } \\
\text { - A lot of people feel it is easier to use coils and } \\
\text { repellent } \\
\text { - If they use expensive insecticides then eventually } \\
\text { they don't use anything at all } \\
\text { - It is more economical to use a net } \\
\text {-A lot of people who do not know of its effective } \\
\text { help in preventing malaria do so because of } \\
\text { ignorance, or use the excuse of funds for its } \\
\text { acquisition as a reason for not using it, they may } \\
\text { resort to coils and locally made insecticide } \\
\text { Local beliefs } \\
\text { - Some play on the idea that they have become } \\
\text { immune to mosquito bites } \\
\text { - Most people do not believe in its effectiveness } \\
\text { because they have not tried it } \\
\text { - The mosquito will come in if there are no nets } \\
\text { on doors or windows } \\
\text { - It is very convenient to use if on the door } \\
\text { or window }\end{array}$ & $\begin{array}{l}\text { - Mothers are usually forwards on such matters } \\
\text { because of their more attentive nature and } \\
\text { want wellbeing for their child, so if they know } \\
\text { about it they will want it } \\
\text { - It allows my family to sleep protected from } \\
\text { the mosquito bite, but if I am away to fish, } \\
\text { for work, my pregnant wife cannot erect } \\
\text { the net } \\
\text { - Any mother will decide on its usage } \\
\text { especially when she understands its } \\
\text { importance }\end{array}$ \\
\hline
\end{tabular}

cess of setting it up is impossible if I am not around for my family". Another interviewee commented: "assembling and dismantling in hot and humid conditions becomes too much of a chore". The effect of this issue is best summarized in this respondent's revealing words: "The most discouraging process of setting it up, most people like me only attempt it once, especially when you believe you have survived all these years without it".

One man said "it is absolutely safe if you use it properly", but nets were considered to be potentially hazardous to young children through entanglement, strangulation, or suffocation $(n=4)$. Several adults mentioned that supervision was required when a young child slept in the net: "they could easily get strangled by it while trying to exit"; "constant supervision is required for an under 5, it can turn it into a danger"; "child could find it strange, hold it and it falls down". The nets were also considered a major fire hazard, which was reported particularly in areas were people relied on a "local lamp" after nightfall: "I knocked over my lamp that almost set my house on fire, that is why I have used my own as a curtain as you can see". Another suggested that nets were a hazard if alcohol had been consumed: "one should not set it up if you have had alcohol'. If there was not a fixed point from which to secure the net, objects were sometimes used for purchase and this was reported as a hazard or destructive to the net because "they are quick to tear from the point of fixture". In 
one case it was reported that hanging the net distorted the walls of the living area and nails were difficult to fix due to materials in use.

\section{Perceived comfort: ventilation and bodily contact}

The nets were perceived to restrict ventilation and in some cases were reported as "claustrophobic" or "confining" and were mentioned as a factor in respiratory problems in a few cases. Some respondents specifically mentioned that nets prevented air from reaching them, or that they needed more air to sleep well and avoid sleep disturbance: "It feels like suffocation"; "limits air access"; "it looks uncomfortable to my eyes". When it is hot and humid, bodily contact with the net is very unpleasant and was reported as a major barrier to use: "the net touches your body and causes irritation"; "it irritates the body"; "it can stick to you when it is hot". Some respondents mentioned that they did not want their children's skin or hair to come into contact with the net and the insecticide that impregnates it, and one respondent was worried about insecticide ingestion, saying that " $a$ young child can chew it". Several reported that they had experienced skin irritation or respiratory problems and considered an ITN to be the cause.

The findings also suggested that outdoor sleeping was very common during the hot season, or when space was limited due to overcrowding (often visitors), or when families had no light and electricity, or were under pressure because of the requirements of farm and fishing work: "when the weather is hot lots of people like to sleep outside"; "when there is no light and the weather is hot in the hot season especially people stay outside on foams, mats, cartons as long as they can into the night"; "as a fisherman I sleep outdoors a lot, especially when I have set up my nets and hooks"; "people sleep outside when there is no electricity, when it is hot or there is no room because of too many visitors". "Airy" sleeping with good ventilation was desired in the hot season and outdoor sleeping was seen as desirable.

\section{Perceived effectiveness of net, local repellents, and coils}

There were mixed responses concerning effective mosquito bite prevention. Several respondents indicated that the net was the most economic and most effective way to prevent mosquito bites, and indicated that correct use and an understanding of this was important. For some respondents, coils and local repellent were considered easier to use but more expensive than maintaining an ITN. Local repellents and mosquito coils were seen to be as effective as nets but mostly when people had not tried a net "it is only those who have not used it that rely on coils and local repellants"; "some don't have the money, some prefer the old way of sprays"; "the cost implications of using repellents and coils is 1,500 Nira monthly [US\$9.75] the person using a net is more economical'. A few indicated that bed net maintenance costs were a barrier compared with the cost of local repellent. One respondent explained, for example, that "most people abandon themselves to the mosquito and take drugs if they get malaria: repellents are too expensive for maintenance".

Frequently cited perceived risks of mosquito entry, were eaves, windows, and "broken ceilings". For most respondents, prevention was mentioned as better than "cure"; "the net does reduce mosquito attacks". As one respondent said, "preventing a mosquito from entering is the best option of all". Nets were considered a preventative measure: "before the window nets, my mum always ensured we were tucked under the nets, for us it was effective" but they were generally not seen as effective because of low usage: "as it stands no one around my neighbourhood, most people have not used a bed net and therefore it cannot be said to be effective"; "quite a lot of riverine communities have not seen a bed net". A few mentioned a belief about natural built up immunity to malaria, "some play with the idea that they are immune to bites", but most were aware of the value of net protection and importance of prevention. Low usage was due to four main barriers: family sleeping arrangements, inconvenience, comfort, and safety.

\section{Discussion}

As indicated by the literature and our findings, the problems of sustained use of bed nets are much more complex than can be addressed by malaria prevention campaigns alone. The present study has highlighted that a number of barriers to net use remain prevalent, and provides some direction for future research. The findings provide some evidence that the bed net is sometimes seen as inconvenient, space consuming, restrictive, and uncomfortable. In what follows we a) locate our findings in the context of existing studies about acceptability and use of bed nets, and b) discuss the key findings from the qualitative data in the light of other published studies, with particular focus on barriers to sustained net use.

\section{The acceptability of bed nets}

Our findings reflect complex everyday issues that influence sustained net use. Several other studies have suggested 
that knowledge of malaria and its prevention alone is not sufficient to sustain motivation to use bed nets, and that often community specific practices reduce the effectiveness of nets. While some studies are now quite dated, they nevertheless offer cumulative evidence of difficulties presented to malaria prevention campaigns. The acceptability and use of ITNs have been studied in diverse communities, for example, Ghana; ${ }^{18}$ Gambia; ${ }^{19}$ Equador, Columbia and Peru; $;{ }^{20}$ Guatemala, ${ }^{21}$ Afghanistan; ${ }^{22}$ Tanzania. ${ }^{23}$ The main motivations for using bed nets have been reported as reduction in nuisance of mosquito; perceived threat of malaria; positive views about preventative benefits; ${ }^{20}$ viewed as a desirable item if all household members can be covered by the net; ${ }^{22}$ added protection for other pests such as bed bugs, ${ }^{23}$ provision of decoration and aesthetic benefit to the home. ${ }^{24}$

There are a limited number of studies about community perceptions of prevention and use of nets in West and East Nigeria. An early survey in Eastern Nigeria ${ }^{24}$ identified factors that discourage optimal bed net use including: desire to sleep outside on very hot nights; perception that sleeping under a net is unduly hot, and worries about the side effects of insecticides. However the positive factors reported in this study included increased social status following purchase of a net and "beautification" of the home with door and window nets. A mixed quantitative and qualitative study of perceptions about malaria prevention of 359 individuals from the rural community of Akwa Ibom State, Niger Delta, ${ }^{25}$ was undertaken before the distribution of insecticide treated nets in the area. Findings suggest that ownership and use of bed nets was non-existent in the community studied, although people were quite knowledgeable about the transmission of malaria. The majority of the sample (70\%) believed the mosquito bite to be the cause, but the remainder attributed malaria to other causes, such as contaminated food/water and bad weather. Overall malaria was believed to be $(96.4 \%)$ preventable. The preventative measures adopted included use of drugs (36\%); mosquito nets on windows and doors (30\%); indoor insecticide spraying (22\%); elimination of mosquito breeding sites (17\%) and burning of coils and herbs (3\%). No one in the sample had slept under a bed net but $57.9 \%$ claimed to have seen one. Most of the sample (78.8\%) were willing to own a net but $21.2 \%$ reported that they would not use one. An earlier study ${ }^{24}$ monitored community response to insecticide impregnated bed nets compared with door and window curtains combined with residual spray, in 12 village clusters in Nsukka Local Government area of Enuga State, Nigeria. Bed nets were perceived as more effective in reducing mosquito bites than curtains or spray. Bed net owners demonstrated a greater knowledge of use and care of nets than did those with curtains. These findings suggest a high level of social acceptability of bed nets, but more recent studies have indicated the difficulties of sustained bed net use in communities, even when nets are initially acceptable. ${ }^{26,27}$ Qualitative methods with an open ended "insider" approach, ${ }^{28}$ have proved particularly beneficial in exploring everyday living and social factors that are significant. ${ }^{29} \mathrm{~A}$ combined qualitative and quantitative study also undertaken in Enugu State, rural south east Nigeria ${ }^{26}$ indicated that while overall net coverage was low, people were knowledgeable about malaria and the benefits of protection against the disease through net use. Various preventative measures were being used, such as coils, window nets, insecticide sprays, with average monthly expenditure on prevention per household 55.55 Naira (US\$0.4), but more than $80 \%$ of people had never purchased a net. Noor et $\mathrm{al}^{27}$ used national household survey data (2005-2009) from 18 malaria endemic African countries to identify ITN use by age and sex: general progress toward Abuja targets was more promising with highest coverage of ITNs in children under 5, but the lowest coverage was 5 to 19 years, rising again in adulthood. In Niger, coverage was comparatively poor; $<10 \%$ of population slept under an ITN and in under fives, 8.7\% slept under a ITN. (This compares with $>20 \%$ coverage in Kenya, Tanzania, Gambia, and Mali.) The authors concluded ${ }^{26}$ that in malaria endemic Africa, school age children are the least protected, and advocated school-based initiatives for delivery of ITNs, and further argued that upscaling malaria control to universal African coverage requires a better understanding of groups who are least protected. They also point to the significance of sharing sleeping structures; young children most often sleep with mothers or both parents, and older children sleep on separate beds or mats.

Our findings indicate that most considered the bed net as useful for keeping mosquitoes out. Previous Nigerian studies have also demonstrated community knowledge about prevention of mosquito bites by nets, for example, spontaneous responses about what people liked about bed nets included prevention of mosquito bites; "kills mosquitoes; prevents malaria; kills other insects". ${ }^{24}$ The findings also indicated that people liked the nets because they beautified their homes, provided warmth, prevented dirt on beds, and aided sleep. In general the sample in this present study were knowledgeable about the cause of malaria and the potential of bed nets to prevent transmission.

However typical living arrangements present barriers to net use and our findings concur with those of Toe et al. ${ }^{29}$ 
Theirs was the first evaluation of motivation to use bed nets undertaken several months after an intensive distribution and educational campaign in south west Burkina Faso. The regular use of bed nets was determined by the organization of the household, particularly in small houses. Toe et $\mathrm{al}^{29}$ draw attention to lowered adherence to bed nets, and potential undermining of sustained net use, due to practical reasons such as net fixing and room arrangements. They concluded that nets that suit living arrangements are needed, and that households with two rooms, rather than a single room, were likely to have more sustained net use. Their sample reported that initially the design of the bed net seemed attractive and pleasant, and people wished to acquire one, then motivation for use began to decline and long-term usefulness was questioned. Sustained bed net use was difficult to achieve, even after intensive promotional programs, and the call for bed nets that are more practical to use, because sleeping followed social rules:

\section{"the obvious problem of having a bulky product suspended \\ in the middle of the room used for many purposes other than sleeping” (p. 6).}

Further support for these findings is provided by a systematic review of qualitative studies (1966-2009), which investigated commonly held beliefs and practices concerning malaria in Sub-Saharan Africa, ${ }^{30}$ Thirty-nine articles were included in the analysis and of these 29 identified barriers to prevention including numerous barriers to the use of bed nets related to ease of use and cost. A survey of 857 households in Ethiopia ${ }^{31}$ demonstrated that while overall net ownership was high, incorrect net use was observed and the authors suggested that assistance with hanging would enhance net use. Similarly, sleeping arrangements, availability of multiple beds and several rooms also determined net use in a study in Ghana. ${ }^{32} \mathrm{~A}$ desire for outdoor sleeping was also reported. Our findings also suggest that a net that is self supporting, available in a range of sizes and which does not take up a lot of space may be preferable. Improved access and exit is potentially offered by pop up nets but these require testing in the field and particularly in areas where electricity is limited. We did not find any other studies which reported concerns about infant potential entanglement in bed nets but hazards to young children are potentially minimized with a pop up design and this net may be more acceptable to parents. A recent study reported that low coverage of the very young in Nigeria is still a problem, for instance in 2004, ${ }^{17} 3.3 \%$ of under fives were sleeping under a net in Nigeria, and $17.9 \%$ of under fives were sleeping under a "baby net". A baby net is a small umbrella net with a frame, which is rarely insecticide treated as the frame precludes this. In a country where progress toward Ajuba targets is being made, albeit slowly, a self-supporting net, which can be treated and manufactured in a variety of sizes to suit a range of age groups may be a useful adjunct to malaria control programs. A pop up net may also enhance coverage for particular groups such as 5- to 19-year-olds, who currently use nets the least in Africa, ${ }^{27}$ and who tend to sleep separately from parents. However further research with purposive sampling to explore gender and age-related issues is needed.

A study of 900 households in 3 villages ${ }^{26}$ showed that window nets were preferred to bed nets (cost was the major barrier). However nursing mothers did use nets for their babies. Qualitative data reported in our present study reveal other barriers including perceptions about the safety of insecticide impregnation and feelings of "being suffocated" while sleeping under the net (see Table 1). However most people were willing to use bed nets if they were affordable and not harmful. Issues of climate, outdoor sleeping and, for men in particular, work away and social activities, affect net use. ${ }^{32}$ A net that could be used both indoors and outdoors may possibly be advantageous, and a self-supporting, sealed pop up net may be easier for older children and women to assemble and may also prevent, for example, sand fly, soldier ants, and reptile infestation. Comfort issues remain an important consideration in the design of preventative bed nets. Perceived lack of ventilation and heat while under the net remain an issue if the net is for use indoors. Our findings and for example a study from Ghana ${ }^{11}$ indicate perceptions about nets being too hot to sleep under. Some previous research has investigated that the preferred net mesh size in various communities and mesh preferences should be considered when selecting net fabric. Manufacturers have tried to address problems of ventilation and heat by increasing mesh size and using durable materials. ${ }^{32} \mathrm{~A}$ few studies have indicated that a dark-colored fabric is preferable, so that the net does not look dirty quickly and therefore requires less frequent washing/retreating. ${ }^{32,33}$ Because of cultural beliefs, white is not an acceptable color in some communities. Atkinson et $\mathrm{al}^{32}$ have also reported that nets that wrinkled, were "stiff", or difficult to "tuck in" were not acceptable. Further research into fabric acceptability and durability is needed and, specifically, what works best in a pop up design suitable for the Niger Delta? Pop up net maintenance and 
insecticide re-impregnation costs continue to be a problem. Other studies ${ }^{18,34}$ have indicated barriers to net maintenance, and therefore further comparative acceptability and cost effectiveness studies are needed.

Nets need care if they are to be effective. Correct bed net use requires 9 steps, as reported in a Nigerian study: ${ }^{24}$ rolling up the net when not in use; rolling out the net carefully at night; tucking in the net partially; tucking the net in fully when in bed; washing instructions; a re-impregnation schedule; inspection for holes; checking for mosquitoes trapped inside; and sleeping away from the edge of the bed. Their study findings indicated that recall of the required steps increased over the 3-monthly monitoring surveys among their sample. A key finding from our present study concerns the difficulty of using a bed net when light is limited due to lack of electric power. A net that allows easy access and that requires fewer procedural steps might enhance use in this situation. A net that can be used inside or outside and that does not take up a lot of space may enhance sustained use, as suggested by Toe et al. ${ }^{29}$

Local beliefs about "having to live with the risk" and have "survived this far" will not be affected by use of pop up nets alone; sustained integrated educational programs are needed, particularly where family sleeping structures determine net coverage of those most at risk. For example, a study ${ }^{35}$ revealed incorrect practices and attitudes about use of nets in the dry season; perceptions of the need to retreat nets, the need for children to nap under nets, and net repair could be improved by community-tailored education and net distribution in Tanzania. Where uptake of ITNs has been low, other preventative measures have been shown to be acceptable, for example, reported high uptake of window screens and ceilings in an urban area of Tanzania, Dar es Salaam, ${ }^{36}$ suggesting that research with a variety of screening methods including a potential pop up net is worthwhile. More recent research ${ }^{37}$ also underlines that sociocultural factors, particularly socioeconomic factors, clearly influence the rate of utilization of ITNs: positive contributors to net use were literacy, economic status, experience of marriage, and employment; negative factors included some cultural beliefs and practices, lack of information and education, and poverty. Our findings and the body of literature available indicate that possible ITN design improvements may have the potential to offer public health gains, but this cannot be in isolation - interventions that have the potential to affect socio-economic factors and community and cultural perceptions are also required.

\section{Limitations}

Due to the study location and context we have not been able to purposively sample, and therefore cannot explore, the affects of gender and age. This exploratory study relies on a convenience sample (because we needed to prioritize access to hard-to-reach samples in the Niger Delta). Subsequently, volunteers participating are mostly male adults and our analysis does not include female perspectives due to sampling limitations. This limits the conclusions that can be drawn from the findings. For example, in this present study the observed importance of structural and inconvenience factors, safety, and comfort may reflect issues of more concern to males than females, due to the gender bias of our sample, but this needs further investigation. Overall the findings are not generalizable to all families in the Delta, but they do highlight issues that are worthy of exploration to help further develop malaria prevention strategies. A more focused purposive sample comprising mothers of under fives, and young people 12 to 19 years may illuminate some further barriers or motivations for use of bed nets, which have not been reported in this study. This would also facilitate more exploration of perceived harm to children and pregnant mothers, for example, worries about safety, insecticides, and affordability. The sample is drawn from a range of areas in the Delta and is not focused on particular groups of villages, and further work within specific locations is required. Focus groups may have uncovered areas of consensus or disagreement and allow exploration of gender and age issues. A researcher from the Delta area, with a greater "insider" perspective, able to spend a prolonged period in the area, would have been able to collect more in-depth data with a wider range of respondents. Instead, we have had to rely on semi-structured interviews and "outreach" supervision of research as a result of UK Foreign Office restrictions on travel to the Delta.

Further qualitative and quantitative research is needed to investigate if barriers related to sustained net use, for instance, sleeping arrangements and perceived hazards, can be overcome by a pop up net. Our findings are not new but suggest, together with the cumulative evidence from other studies, that there remain important barriers to preventative measures for the successful control of malaria. These require further investigation alongside potential solutions. We have been particularly interested in the perceived problems of bed nets with a view to helping with the design of a pop up net and this will have influenced the focus of the data collection. Nonetheless, the findings are of general interest and are congruent with existing published empirical work. 


\section{Conclusion}

A considerable body of evidence indicates that socio-cultural factors influence malaria control. The perceptions of communities about transmission, prevention, and treatment of malaria are central to understanding how interventions can be effectively introduced to control the disease. Successful control of malaria and scale up of ITN coverage relies on community perceptions and practice. The present study has illuminated a number of issues and concerns that remain barriers to sustained bed net use (typical sleeping arrangements affect net use; nets consume family space; bed nets are perceived as arduous to set up and not easy to use, particularly where electric light is limited; hazards; comfort; and local beliefs). We have also clarified further questions to be considered in net design and future research studies:

- How can a pop up net overcome these barriers, if at all?

- Will a self-supporting net increase accessibility in and out and enhance sustained motivation to use a net?

- Can perceptions of comfort and safety be improved through improved design of the net?

- What net color and mesh size used in a pop up net is widely acceptable in the Niger Delta?

- Are there gender differences in net acceptability?

Better ITN net usage can possibly be afforded if a pop up net design can minimize the negative impacts of bed nets on everyday family life, improve safety, and increase positive perceptions about ventilation, comfort, and cost of maintenance, but we do not know enough yet to suggest if a pop up net can overcome these barriers. Whatever barriers can be overcome, it is clear that malaria control programs need to be supplemented with ongoing educational programs on correct use of ITNs if successful prevention is to be scaled up. The present descriptive study highlights the need for further research on human concerns and everyday life issues which contribute to sustained use of nets or which, conversely, present significant barriers.

The exploratory findings from this present study will help with the development of a larger study focused on factors impeding sustained use of bed nets, reasons for potential lack of use, and potential acceptability or otherwise of an alternative net. Our long-term aim is to investigate the acceptability of a pop up self-supporting insecticide-treated net, and to evaluate its potential use in the Niger Delta, particularly for under fives. However, this is not the focus of this present paper. The information gained in this present study, in addition to the literature, will help in designing a survey and further qualitative study and also help with aspects in the design of a pop up net that will be field tested for viability in the Delta region in the future.

\section{Authors' contributions}

KT Galvin designed the data collection interview guide, analyzed the data and was responsible for drafting the paper and approving its content. N Petford was responsible for drafting the paper and approving its content. F Ajose was responsible for drafting the paper and approving its content. D Davies accessed the sample in the Niger Delta, collected the data, and approved the final draft.

\section{Acknowledgment}

Development Partnerships in Higher Education British Council (DelPHE 641).

\section{Disclosure}

Bournemouth University Innovations Ltd has a commercial interest in developing pop up insecticide treated nets. No authors received any financial or other incentives to undertake this work. The study is part of a Development Partnerships in Higher Education project, funded by the British Council.

\section{References}

1. World Health Organisation. A global strategy for malaria control. Geneva, Switzerland; 1993. http://www.rollbackmalaria.org/gmap/ index.html. Accessed April 26, 2010.

2. UNICEF: Malaria: A Major Cause of Child Death and Poverty in Africa. UNICEF. New York, NY; 2004.

3. Oresanya OB, Hoshen M, Sofola OT. Utilization of insecticide-treated nets by under five children in Nigeria. Assessing progress towards Abuja targets. Malaria J. 2008;7:145.

4. Gillett JD. The behaviour of Homo sapiens, the forgotten factor in the transmission of tropical disease. Trans R Soc Trop Med Hygiene. 1985; 79:12-20.

5. Agyeong IA. Malaria: ethnomedical perceptions and practice in an Adange farming community and implications for control. Social Science and Medicine. 1992;35:131-137.

6. Ruebush TK, Weller SC, Klien RE. Knowledge and beliefs about malaria on the Pacific Coastal plain of Guatemala. Am J Trop Med Hyg. 1992;46: 451-459.

7. Ongore D, Kamunvi F, Knight R, Minawa A. A study of knowledge, attitudes and practices (KAP) of a rural community on malaria and the mosquito vector. East Afr Med J. 1989;66:79-89.

8. Aikins MK, Pickering H, Greenwood BM. Attitudes to malaria, traditional practices and bednets (mosquito nets) as vector control measure: a comparative study in five West African countries. J Trop Med Hyg. 1994;97:81-86.

9. Klien RE, Wellwe SC, Zeissig R, Richards FO, Ruebush TK. Knowledge, Beliefs and Practices in Relation to Malaria transmission and vector control in Guatemala. Am J Trop Med Hyg. 1995;52:383-388.

10. Mwenesi H, Harpham T, Snow RW. Child malaria treatment practices among mothers in Kenya. Soc Sci Med. 1995;40: 1271-1277.

11. Ahorlu CK, Dunyo, SK, Afai EA, Koram KA, Nkrumah FK. Malaria - related beliefs and behaviour in southern Ghana: implications for treatment, prevention and control. Trop Med Int Health. 1997;2: 488-499. 
12. Yeneneh H, Gyorkos TW, Joseph L, Pickering J, Tedla S. Antimalarial drug utilization by women in Ethiopia: a knowledge- attitudes- practice study. Bull World Health Org. 1993;71:763-772.

13. World Health Organization. African Summit on Roll Back Malaria. Geneva Switzerland; 2002. http://www.rollbackmalaria.org/docs/ abuja_brf2702.htm. Accessed April 26, 2010.

14. Onwujekwe O, Chima RI, Okonkwo PO. Economic burden of malaria illness versus that of a combination of all other illnesses: a study in five malaria holo-endemic communities. Health Policy. 2000;54: 43-159.

15. Agwu N, Amadi M, Bertram EB, Nwoke O, Ikechukwu M. Emerging trends in clinical malaria in parts of abia state: influence of environmental, human and socio-cultural factors. Res J Med Sci. 2007;1:1-5.

16. World Health Organization. Roll Back Malaria. Geneva, Switzerland; 2002. http://www.rollbackmalaria.org/cmc_upload/0/000/015/372/ RBMInfosheet_1.htm. Accessed April 26, 2010.

17. Baume CA, Marin MC. Gains in awareness, ownership and use of insecticide-treated nets in Nigeria, Senegal, Uganda and Zambia. Malaria J. 2008;7:153.

18. Binka FN, Adongo P. Acceptability and use of insecticide impregnated bednets in northern Ghana. Trop Med Int Health. 1997;2:499-507.

19. D’Alessandro U, Aikins MK, Langerock, P, Bennett S, Greenwood BM Nationwide survey of bednet use in rural Gambia. Bull World Health Org. 1994;72:391-394.

20. Kroeger A, Mancheno M, Alarcon J, Pesse K. Insecticide-impregnated bed nets for malaria control: varying experiences from Equador, Colombia, and Peru concerning acceptability and effectiveness. Am J Trop Med Hyg. 1995;53:313-323.

21. Richards FO, Klein RE, Zea FR, et al. Permethrin-impregnated bed nets for malaria control in northern Guatemala: epidemiological impact and community acceptance. Am J Trop Med Hyg. 1993;49: 410-418.

22. Howard N, Ahmad S, Jones C, Rowland M. Malaria control under the Taliban regime: insecticide - treated net purchasing, coverage, and usage among men and women in eastern Afghanistan. Malaria J. 2010;9:7.

23. Lines JD, Myamba J, Curtis CF. Experimental hut trials of Permethrin impregnated mosquito nets and eave against malaria vectors in Tanzania. Med Vet Entomol. 1987;1:37-51.

24. Brieger WR, Onyido OE, Sexton JD, Ezike VI, Breman JG, Ekanem OJ. Monitoring community response to malaria control using insecticideimpreganted bed nets, curtains and residual spray at Nsukka, Nigeria. Health Educ Res: Th Pract. 1996;11:133-145.
25. Ukpong IG, Opara KN, Usip LPE, Ekpu FS. Community perceptions about malaria, mosquito and insecticide treated nets in a rural community of Niger Delta: implications for control. Res J Parasit. 2007;2:13-22.

26. Onwujekwe O, Uzochukwu B, Ezumah N, Shu E. Increasing coverage of insecticide-treated nets in rural Nigeria: implications of consumer knowledge, preferences and expenditures for malaria prevention. Malaria J. 2005;4:29.

27. Noor AM, Kirui VC, Brokker SJ, Snow RW. The use of insecticide treated nets by age: Implications for universal coverage in Africa. BMC Public Health. 2009;9:369.

28. Holloway I. A-Z of Qualitative Research in Healthcare. 2nd edition. Oxford: Blackwell; 2008.

29. Toe LP, Skovmand O, Roch Dabire K, et al. Decreased motivation in the use of insecticide- treated nets in a malaria endemic area in Burkina Faso. Malaria J. 2009;8:175.

30. Maslove DM, Mnyusiwalla A, Mills EJ, McGowan J, Attaran A, Wilson K. Barriers to the effective treatment and prevention of malaria in Africa: a systematic Review of qualitative studies. BMC Int Health Hum Rights. 2009;9:26.

31. Baume CA, Reithinger R, Woldehanna S. Factors associated with use and non-use of mosquito nets owned in Oromia and Amhara Regional States, Ethiopia. Malaria J. 2009;8:264.

32. Atkinson JA, Bobogare A, Fitzgerald L, et al. A qualitative study on the acceptability and preference of three types of long-lasting insecticide - treated bed nets in Solomon Islands: implications for malaria elimination. Malaria J. 2009;8:119.

33. Gyapong M, Gyapong JO, Amankwa J, Asedam J, Sory E. Introducing insecticide - impregnated bednets in an area of low bednet usage: an exploratory study in the north-east Ghana. Trop Med Int Health. 1996;1:328-333.

34. Wince PJ, Makembe AM, Makame VR, et al. Social and cultural factors affecting rates of regular retreatment of mosquito nets with insecticide in Bagamoyo District, Tanzania. Trop Med Int Health. 1997;2:760-770.

35. Widmar M, Nagel CJ, Ho DY, Benziger PW, Henning N. Determining and addressing obstacles to the effective use of long-lasting insecticideimpregnated nets in rural Tanzania. Malaria J. 2009;8:315.

36. Ogoma SB, Kannady K, Sikulu M, et al. Window Screening, ceilings and closed eaves as sustainable ways to control malaria in Dar es Salaam, Tanzania. Malaria J. 2009;8:221.

37. Jombo GTA, Mbaawuaga EM, Gyuse AN, et al. Socio-cultural factors influencing insecticide treated bed net utilisation in a malaria endemic city in north-central Nigeria. Asian Pacific J Trop Med. 2010;3(5):402-406.
Journal of Multidisciplinary Healthcare

\section{Publish your work in this journal}

The Journal of Multidisciplinary Healthcare is an international, peerreviewed open-access journal that aims to represent and publish research in healthcare areas delivered by practitioners of different disciplines. This includes studies and reviews conducted by multidisciplinary teams as well as research which evaluates the results or conduct of such teams or health-

\section{Dovepress}

care processes in general. The journal covers a wide range of areas and welcomes submission from practitioners at all levels, from all over the world. The manuscript management system is completely online and includes a very quick and fair peer-review system. Visit http://www.dovepress.com/ testimonials.php to read real quotes from published authors. 